\title{
Antioxidant, Anti-inflammatory and Anticancer Properties of Mango Fruit
}

\author{
Abdullah Bin Masood, Shahid Mahmood Rana*, Muhammad Qamrosh Alam, Wajiha Saeed, Iqra and \\ Sidra-Tul-Muntiha \\ Institute of Food Science and Nutrition, University of Sargodha, Sargodha, Pakistan \\ *Corresponding Author: Shahid Mahmood Rana, Institute of Food Science and Nutrition, University of Sargodha, Sargodha, Pakistan.
}

Received: September 10, , 2019; Published: September 26, 2019

DOI:_10.31080/ASNH.2019.03.0465

\begin{abstract}
The mango (Mangifera indica L.) is worldwide important tropical fruit widespread selling, with massive production, extensive nutrient supply, and welfare to human health. Mango peel and seed kernels which are considered as waste, but have high purposeful and nutritional potential. Mango plants produce plump nugget fruits which are rich in phytochemicals with an acknowledged nutritional worth for its high ratio of polyphenolics and vitamins. This review provides an overview of the antioxidant, antiinflammatory, and anticancer properties of mango, a fruit that should be included in everyone's diet for its multifaceted biochemical actions and health-enhancing properties. Regarding medical importance human bacterial and fungal pathogens are influenced by the extracts of mango seed kernel, hence, biochemical characteristics and antimicrobial potentials are evaluated.
\end{abstract}

Keywords: Mangifera indica; Mango; Production

\section{Introduction}

Mango fruit produced in South Asia and then it was spread to the whole world [1]. Nowadays, the mango fruit is produced by 90 countries in the world, the Asian continent is the biggest mango producing continent that produces almost $77 \%$ of the entire world's production [2]. The maximum variability of mango occurs in Malaysia, produces predominantly about 28 species of mango in the region of peninsular area [3]. The Mangifera genus contains about 69 species and generally limited to sweltering Asia [3].

At the present time, medicinal plants and bioactive phytocompounds are used at more rising interest. For the survival of the humans, plant kingdom plays a role of safeguarding all over past times, as documented. From the thousands of years' plants are being exploited in traditional medicine system all over the world and providing new cures to mankind. Due to increase in the drug resistance progress in the pathogens and in addition to adverse side effects of certain antimicrobial agents in humans, it is being obligatory, to search new agents are necessary that are superior, inexpensive and without any side effect, targeting the treatment of infectious diseases particularly in progressing countries. Many infections are cured with the vast variety of plant/natural products. Bacteria, Fungi, Viruses and Pests are inhibited by Phytoconstituents. The one of the most essential sweltering fruits in the world is the mango (Mangifera indica L.), appreciations to its pleasurable flavor, fragrance and extraordinary nutritious significance [4].
Mango is abundant in sugars, water, minerals, fiber, antioxidants and vitamins [5]. Mango is a rich source of carbohydrates (58 - 80 $\%)$ and protein (6-13\%) and contains profile of essential amino acids and lipids (6-16\%); it is rich in oleic and stearic acids [6]. Mango has anticancer action counter to breast and colon cancer [7] and antimicrobial activity counter to Gram positive and Gram negative bacteria [8], which is credited to its high antioxidant capability. An antidiarrheal influence has been stated and credited to its extraordinary tannin content [9]. In addition, the physicochemical characteristics of mango seed fat are very alike to those of commercial cocoa butter [10]. Aqueous extract of mango bark is used in Cuba by patients in raised stress pain [11]. Extracts of various portions of Mangifera indica L. contains numerous natural and pharmacological possessions [12]. The alcoholic extract of seeds demonstrated anti-inflammatory action in severe, sub-acute and lingering cases of inflammation [13].

Mango is considered as the king of fruits because of its chemical make-up. This is the difference that marks it the second greatest merchandized sweltering fruit in the world and fifth in over-all production [14]. Mango can be tinned, chilled treated as concentrates, pulped, dried out, slightly treated, or ready as juices and jams [15]. About one million tons of mango seeds are made as rubbishes yearly, and these are not presently consumed for any commercial commitments [16]. 


\section{Conclusions}

Crude methanolic mango seed kernel extracts were analyzed for the $\mathrm{s}$. The free radical sifting action was determined by 2,2-Diphenyl-1-picrylhydrazyl (DPPH) test. Disc diffusion test assessed the Antibacterial activity with three pathologically important bacterial pathogens such as methicillin resilient Staphylococcus aureus, Escherichia coli, Pseudomonas aeruginosa and Vibrio vulnificus. Extracts of these seed kernels rich in bioactive compounds are ultimate raw constituents with good antioxidant stuffs. In command to define their potential use.

\section{Bibliography}

1. Litz R E. "The mango: botany, production and uses" (2009).

2. FAOSTATS Food and agriculture organization of the United nations. [Report]- United nations (2010).

3. Ian SE. "Species profiles for pacific island agroforestry". Mangifera Indica (mango) (2006).

4. Ibarra-Garza., et al. "Effects of postharvest ripening on the nutraceutical and physicochemical properties of mango (Mangifera indica L. cv Keitt)". Postharvest Biology and Technology 103 (2015): 45-54.

5. Tharanathan R N., et al. "Mango (Mangifera indica L.), "The king of fruits"-An overview". Food Reviews International 22 (2006): 95-123.

6. Siaka D. "Potential of mango (Mangifera indica) seed kernel as feed ingredient for poultry- a review”. World's Poultry Science Journal 70 (2014).

7. Kathleen P. "Mango fruit been found to prevent or stop certain colon and breast cancer cells in the lab". Science Daily 12 (2010): 1 .

8. Khammuang S and Sarnthima R. "Antioxidant and antibacterial activities of selected varieties of thai mango seed extract". Pakistan Journal Pharmaceutical Science 24 (2011).

9. Rajan S., et al. "Antidiarrhoeal efficacy of Mangifera indica seed kernel on Swiss albino mice". Asian Pacific Journal of Tropical Medicine 5 (2012).

10. Jahurul M., et al. "Mango (Mangifera indica L.) by-products and their valuable components: A review". Food Chemistry 183 (2015).

11. Garrido G., et al. "Analgesic and antiinflammatory effects of Mangifera indica L. extract (Vimang)". Wiley Inter Science Journal 15 (2001): 18-21.

12. Barreto JC., et al. "Characterization and quantitation of polyphenolic compounds in bark, kernel, leaves, and peel of mango (Mangifera indica L.)". Journal of Agriculture and Food Chemistry 56 (2008): 5599-5610.
13. Shah KA., et al. "Mangifera Indica (Mango)". Pharmacognosy Review 4 (2010): 42-48.

14. FAOSTAD. F. and A. organization of the united nations. FAO (2015).

15. Masibo M and He Q. "Mango bioactive compounds and related nutraceutical propertiesda review". Food Reviews International 25 (2009).

16. Leanpolchareanchai J., et al. "Microemulsion system for topical delivery of thai mango seed kernel extract: Development, physicochemical characterisation and ex vivo skin permeation studies". Molecules 19 (2014).

\section{Volume 3 Issue 10 October 2019}

(C) All rights are reserved by Shahid Mahmood Rana., et al. 